\title{
Georges Chastelain, Le livre de Paix
}

\author{
Maria Colombo Timelli
}

\section{(2) OpenEdition}

\section{Journals}

\section{Édition électronique}

URL : http://journals.openedition.org/studifrancesi/9803

DOI : 10.4000/studifrancesi.9803

ISSN : 2427-5856

\section{Éditeur}

Rosenberg \& Sellier

\section{Édition imprimée}

Date de publication : 1 octobre 2007

Pagination : 421-422

ISSN : 0039-2944

\section{Référence électronique}

Maria Colombo Timelli, « Georges Chastelain, Le livre de Paix », Studi Francesi [En ligne], 152 (LI | II) |

2007, mis en ligne le 30 novembre 2015, consulté le 07 janvier 2021. URL : http://

journals.openedition.org/studifrancesi/9803 ; DOI : https://doi.org/10.4000/studifrancesi.9803

Ce document a été généré automatiquement le 7 janvier 2021.

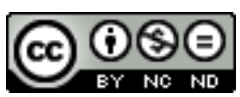

Studi Francesi è distribuita con Licenza Creative Commons Attribuzione - Non commerciale - Non opere derivate 4.0 Internazionale. 


\title{
Georges Chastelain, Le livre de Paix
}

\author{
Maria Colombo Timelli
}

\section{RÉFÉRENCE}

Georges Chastelain, Le livre de Paix, édité par Tania Van Hemelryck, Paris, Honoré Champion Éditeur, 2006 («Classiques français du Moyen Âge», 148), pp. 187.

1 Après la destruction du manuscrit de Tournai, seule la copie de Florence (Biblioteca Laurenziana, Mediceo-Palatino 120) transmet le texte du Livre de Paix, traité allégorique que Georges Chastelain rédigea au lendemain du traité de paix signé à Péronne (14 octobre 1468) par Charles le Téméraire et Louis XII. Il s'agit d'un songe politique mettant en place une fiction allégorique et un certain nombre de personnifications, selon un mode d'écriture qui au $\mathrm{xv}^{\mathrm{e}}$ siècle a une longue tradition derrière lui. Ici l'allégorie se fonde sur une architecture précise, un 'pavillon', construction éphémère s'il en est, image qui souligne le caractère fragile et précaire de toute entreprise pacifique. La description du pavillon dans le Prologue permet d'avoir accès à la 'senefiance' du texte et à l'interprétation des événements auxquels Chastelain fait allusion: les quatre pans, respectivement bleu, blanc, rouge, or, symbolisent les quatre phases de la paix traditionnelle ('Humiliacion de courages', 'Satisfaction de personnes', 'Obligation de parolles', 'Execution de promesses'); chaque pan est soutenu par deux cordes ('Cremeur de Dieu' et 'Congnoissance de soy mesmes' pour le premier; 'Consideration juste' et 'Conclusion necessaire' pour le deuxième; 'Verité cordiale' et 'Amisté liberale', 'Regart a propre honneur' et 'Inspection en commune salut' pour les deux derniers), alors que le mât central, qui soutient l'ensemble du pavillon en devenant le fondement de la paix, ne peut que se rapporter à la confiance ('Confidence a terme ou Confiance a l'aventure'). L'entrée du narrateur dans le pavilion (Partie I), où il entend l'exhortation que Dame Paix adresse au roi de France et au due de Bourgogne, permet à Chastelain d'exprimer, sous la forme de l'ironie, ses propres doutes sur les véritables intentions pacifiques des deux Princes et sur les fondements de la paix de Péronne. Le débat qui occupe la Partie II constitue le cœur du traité: l'Acteur assiste maintenant à la 'disputatio' entre deux entités, 'Sens superficiel' et 'Entendement 
penetrant', sorties de son propre corps; encore une fois, la faiblesse des arguments de l'un face à la démonstration serrée de l'autre permet à l'auteur d'affirmer sa propre défiance à l'égard de la paix qui vient d'être signée. Ce n'est qu'à ce moment (Partie III) que le narrateur s'exprime enfin, pour expliciter les principes de toute paix, en passant en revue les images proposées pour les 'traduire' et les appliquer au traité de 1468.

Comme le souligne Tania Van Hemelryck dans une Introduction dense et éclairante (pp. 27-61), tout se tient dans l'édifice construit par Georges Chastelain: il y a pleine cohérence entre domaine architectonique, allégorie, réalité historique: il n'est pas exagéré, par conséquent, de définir cet ouvrage comme «un tour de force rhétorique» (p. 61).

3 L'édition comprend une rapide description du manuscrit (pp. 9-13: l'éditrice transcrit aussi celle du ms. de Tournai, perdu, par Paul Faider); quelques petites fautes se sont glissées dans la description des aquarelles qui illustrent le ms. de Florence: celle du f. $514^{\mathrm{v}}$ est manifestement incomplète (la dame «tient les mains des deux personnages», alors que seul Louis XI est cité) et celles des ff. $561^{v}$ et $562^{v}$, dont les descriptions ne sont pas bien séparées (celle du f. $561^{v}$ doit continuer jusqu'à «cf. position des mains», alors que celle du f. $562^{v}$ doit commencer par «un pavillon rectangulaire...»). Suivent une rapide présentation des lieu et date de composition du traité (pp. 15-17) et une étude de la langue (pp. 19-26: surtout phénomènes graphiques-phonétiques typiques de la 'scripta' du moyen français commun, avec quelques traits picardisants). La bibliographie est nécessairement très limitée: le lecteur est invité à se rapporter à celles réunies par Susanna Bliggenstorfer (1988), Graeme Small (1997), Estelle Doudet (2005). Le texte est accompagné d'un apparat critique en bas de page (uniquement pour les leçons rejetées et pour des remarques sur l'état du manuscrit) et de notes explicatives essentielles (pp. 151-161; les renvois aux chapitres 52 et 53 du texte sont à corriger en 53 et 54); quant au glossaire (pp. 163-182), si les critères de sélection ne sont pas explicités, toutes les occurrences sont données. L'index des noms propres occupe les pp. 183-185.

Grâce à l'édition de Tania Van Hemelryck et à son affection pour le «umble George» (c'est ainsi que le Livre de Paix est signé), nous avons maintenant accès au seul texte de Chastelain sur la paix de Péronne, puisque la partie correspondante de la Chronique ne nous est pas parvenue. 